\title{
Hemoperfusion for Hodgkin Lymphoma-associated Hemophagocytic Lymphohistiocytosis
}

\author{
Raine Tatara ${ }^{1}$, Makoto Sato ${ }^{1}$, Shin-ichiro Fujiwara ${ }^{1}$, Iekuni $\mathrm{Oh}^{1}$, Kazuo Muroi ${ }^{2}$, \\ Keiya Ozawa ${ }^{1}$ and Tadashi Nagai ${ }^{1}$
}

\begin{abstract}
Hemophagocytic lymphohistiocytosis (HLH), which is associated with various underlying conditions, is characterized by hypercytokinemia. Because it is frequently lethal, immediate mitigation of the hypercytokinemia is vital to save patients, particularly when treatments for the patient's underlying condition are ineffective on HLH. We herein present a case of Hodgkin lymphoma associated with HLH in which the HLH did not improve even after chemotherapy. We attempted to save the patient using hemoperfusion with a polymyxin B-immobilized fiber column to remove cytokines; following this treatment, the patient rapidly recovered. Hemoperfusion may be a strategic method to rescue intractable HLH patients.
\end{abstract}

Key words: hemophagocytic lymphohistiocytosis, polymyxin B-immobilized fiber column, Hodgkin lymphoma, hypercytokinemia, hemoperfusion

(Intern Med 53: 2365-2368, 2014)

(DOI: 10.2169/internalmedicine.53.2457)

\section{Introduction}

Hemophagocytic lymphohistiocytosis (HLH), also referred to as hemophagocytic syndrome, is characterized by phagocyte activation caused by hypercytokinemia, or cytokine storm. In addition to phagocytosis of the blood cells in bone marrow by monocyte-macrophage lineage cells, HLH shows a variety of clinical symptoms including fever and hepatosplenomegaly (1). HLH is classified into two groups: familial and acquired (2). Acquired HLH is associated with various diseases including viral infections, autoimmune disorders and malignant tumors such as malignant lymphoma. While the virus-associated type is mainly found in young people, the malignant lymphoma-associated type is most common in adults (3). Although various types of lymphomas, such as intravascular B cell and extranodal NK/T-cell lymphoma, could be underlying diseases for HLH, Hodgkin lymphoma-associated HLH is rare (3).

Although HLH is frequently lethal, effective treatments for the patient's underlying condition may improve its clinical symptoms. However, if such treatments show little or no effect on HLH, immediate mitigation of the cytokine storm is vital to save patients. In fact, patients with Hodgkin lymphoma and HLH have often shown poor prognosis due to the rapid progression of HLH even after chemotherapy $(4,5)$.

We herein report a case of Hodgkin lymphoma-associated HLH in which HLH persisted after initial chemotherapy. We performed hemoperfusion using a polymyxin B-immobilized fiber column to control the hypercytokinemia. With this treatment, the patient's condition rapidly recovered, and we successfully treated him.

\section{Case Report}

A 40-year-old man was admitted to our hospital in March 2012 with a three month history of high fever and body weight loss. The laboratory examinations revealed extremely high levels of C-reactive protein, lactate dehydrogenase, ferritin and soluble interleukin-2 receptor as well as pancytopenia (Table). The bone marrow aspiration revealed the presence of normocellular bone marrow in which activated macrophages phagocytized the erythrocytes and platelets (Fig. 1). In addition, computed tomography of the abdomen revealed hepatosplenomegaly as well as swelling of the

${ }^{1}$ Division of Hematology, Jichi Medical University, Japan and ${ }^{2}$ Division of Cell Transplantation and Transfusion, Jichi Medical University, Japan Received for publication January 9, 2014; Accepted for publication April 7, 2014

Correspondence to Dr. Tadashi Nagai, t-nagai@jichi.ac.jp 
Table. Laboratory Data of the Patient on Admission

\begin{tabular}{lrlrlr}
\hline WBC & $9,000 / \mu \mathrm{L}$ & CRP & $19.4 \mathrm{mg} / \mathrm{dL}$ & Fe & $26 \mu \mathrm{g} / \mathrm{dL}$ \\
Stab. & $36.0 \%$ & TP & $5.0 \mathrm{~g} / \mathrm{dL}$ & Ferritin & $16,997 \mathrm{ng} / \mathrm{mL}$ \\
Seg. & $46.0 \%$ & Alb & $2.4 \mathrm{~g} / \mathrm{dL}$ & sIL-2R & $20,500 \mathrm{U} / \mathrm{mL}$ \\
Mono. & $13.0 \%$ & $\mathrm{Cr}$ & $0.60 \mathrm{mg} / \mathrm{dL}$ & Anti-nuclear antibody & $(-)$ \\
Lym. & $5.0 \%$ & UA & $2.7 \mathrm{mg} / \mathrm{dL}$ & HBs Antigen & $(-)$ \\
RBC & $277 \times 10^{4} / \mu \mathrm{L}$ & Total-bilirubin & $2.08 \mathrm{mg} / \mathrm{dL}$ & HCV Antibody & $(-)$ \\
Hb & $8.2 \mathrm{~g} / \mathrm{dL}$ & Indirect-bilirubin & $1.10 \mathrm{mg} / \mathrm{dL}$ & Procalcitonin & $1.37 \mathrm{ng} / \mathrm{mL}$ \\
Ht & $24.1 \%$ & AST & $64 \mathrm{mU} / \mathrm{mL}$ & Endotoxin & $<0.8 \mathrm{pg} / \mathrm{mL}$ \\
Platelets & $4.8 \times 104 / \mu \mathrm{L}$ & ALT & $21 \mathrm{mU} / \mathrm{mL}$ & $\beta$ D-glucan & $6.7 \mathrm{pg} / \mathrm{mL}$ \\
Reticulocyte & $1.0 \%$ & LDH & $384 \mathrm{mU} / \mathrm{mL}$ & CMV antigenemia & $(-)$ \\
PT-INR & 1.47 & ALP & $668 \mathrm{mU} / \mathrm{mL}$ & EB-VCA IgG & X 160 \\
APTT & $63.0 \mathrm{sec}$ & Na & $123 \mathrm{mmoL} / \mathrm{mL}$ & EB-VCA IgM & $(-)$ \\
Fib. & $420 \mathrm{mg} / \mathrm{dL}$ & $\mathrm{K}$ & $3.7 \mathrm{mmoL} / \mathrm{mL}$ & EBNA & X 20 \\
FDP & $5.8 \mu \mathrm{mL}$ & $\mathrm{Cl}$ & $88 \mathrm{mmoL} / \mathrm{mL}$ & EBV-DNA & $1.2 \times 10^{2} \mathrm{copy} / 10^{6}$ \\
& & $\mathrm{Ca}$ & $7.0 \mathrm{mg} / \mathrm{dL}$ & cells & $(-)$ \\
\hline
\end{tabular}

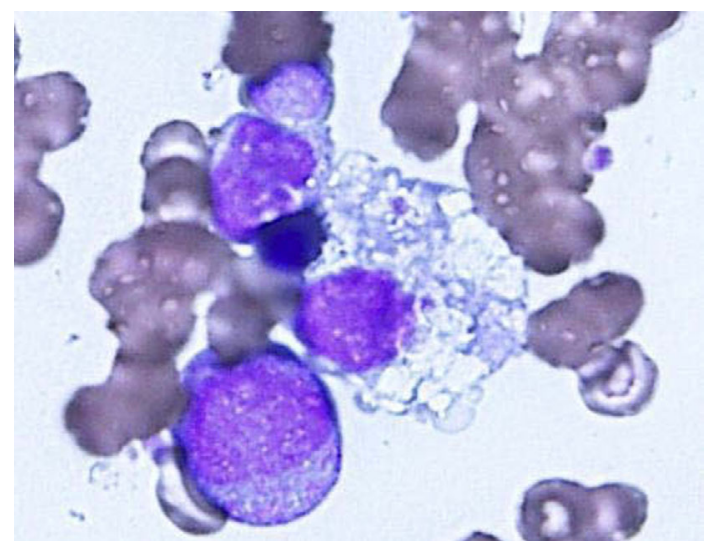

Figure 1. Bone marrow aspiration revealed phagocytosis of the blood cells (Wright-Giemsa, original magnification 1,000x).

para-aortic lymph nodes. Taken together, a diagnosis of HLH according to the HLH-2004 diagnostic guidelines was established (1).

The patient also had cervical and axillary lymphadenopathy. The histological examination of an excised right axillary lymph node showed many large atypical cells, consistent with Reed-Sternberg cells, which infiltrated around the necrotic tissue (Fig. 2A). The immunohistochemical studies showed positivity for CD30 (Fig. 2B), Epstein-Barr Virus (EBV)-encoded RNA (EBER)1 (Fig. 2C), and CD15 staining in the large cells. Based on these findings, we diagnosed the patient as having HLH with underlying Hodgkin lymphoma.

Before the lymphoma diagnosis, we treated the patient with steroid pulse therapy (methylprednisolone $1 \mathrm{~g} /$ day for three days) for HLH; however, it was not effective. After the diagnosis, the patient underwent chemotherapy consisting of doxorubicin, bleomycin, vinblastine and dacarbazine (ABVD), which is the standard chemotherapy regimen for Hodgkin lymphoma (6). Since his lymph nodes decreased in size after the initiation of chemotherapy, it was likely that the chemotherapy had an assertive therapeutic effect on the Hodgkin lymphoma. Nevertheless, his circulatory dynamics worsened, thus resulting in the appearance of hypoxemia, a significant reduction of blood pressure, and an increase in body weight due to fluid retention. Therefore, we began the administration of dopamine and oxygen. It was unlikely that chemotherapy induced tumor lysis syndrome in our patient because his serum potassium, calcium, creatinine and uric acid levels were not markedly changed after chemotherapy. We therefore believed that these clinical symptoms were due to the continuation of HLH.

Considering the refractory state of HLH and his poor general condition, we hypothesized that the immediate suppression of the hypercytokinemia would alleviate his symptoms. Accordingly, we commenced hemoperfusion using a polymyxin B-immobilized fiber column because this column had been used previously to remove cytokines in patients with adult respiratory distress syndrome (7) and septic shock $(8,9)$. With this treatment, his circulatory dynamics rapidly recovered and the clinical symptoms related to circulatory failure disappeared. Furthermore, HLH-related laboratory abnormalities, such as increased serum ferritin levels, also improved (Fig. 3). Following ABVD therapy, the patient achieved complete remission of Hodgkin lymphoma, and after polymyxin $\mathrm{B}$ hemoperfusion he recovered from HLH with no further recurrence.

\section{Discussion}

Hodgkin lymphoma-associated HLH is rare with only a limited number of reported cases (3-5). Those reports revealed that the mixed cellularity type and lymphocytedepleted type are two major types of Hodgkin lymphoma that accompany HLH. In addition, most cases showed Epstein-Barr virus to be present in the Hodgkin cells or Reed-Sternberg cells $(4,5,10)$. Consistent with these findings, the pathological diagnosis of our patient was the mixed cellularity type in which Reed-Sternberg cells were positive for EBER1 staining.

We treated the patient with ABVD therapy, which is the standard chemotherapy regimen for Hodgkin lymphoma (11). Since his lymph nodes reduced in size after the initiation of chemotherapy, it was likely that the chemother- 


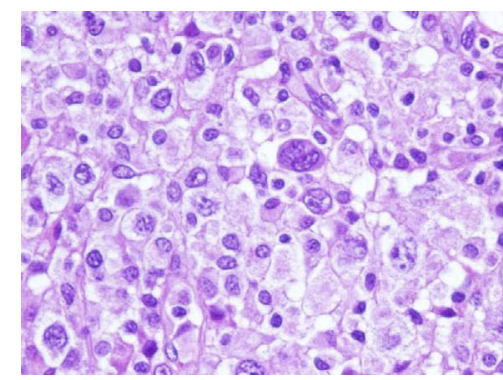

(A)

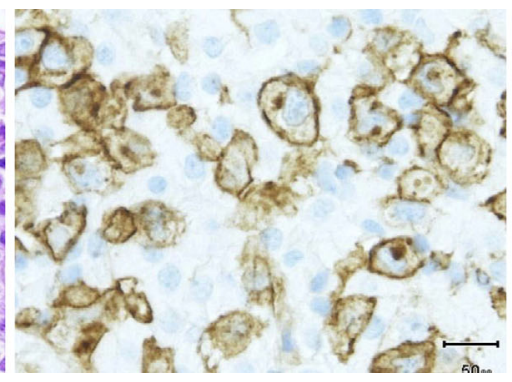

(B)

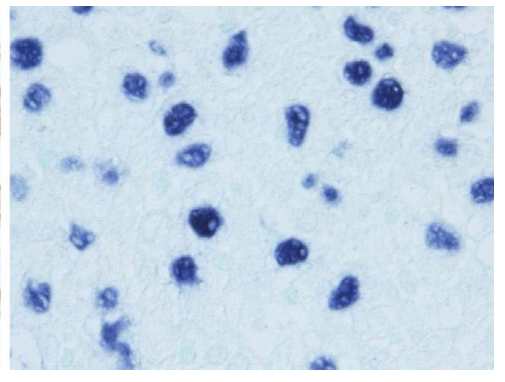

(C)

Figure 2. Histological study of a biopsy specimen taken from an axillary lymph node. (A) Many large, atypical cells infiltrated around the necrotic tissue. Reed-Sternberg cells were also seen (Hematoxylin and Eosin staining, original magnification 400x). (B, C) Immunohistochemistry showed that the large cells were positive for CD30 (B) and EBER1 (C) (original magnification 400x).

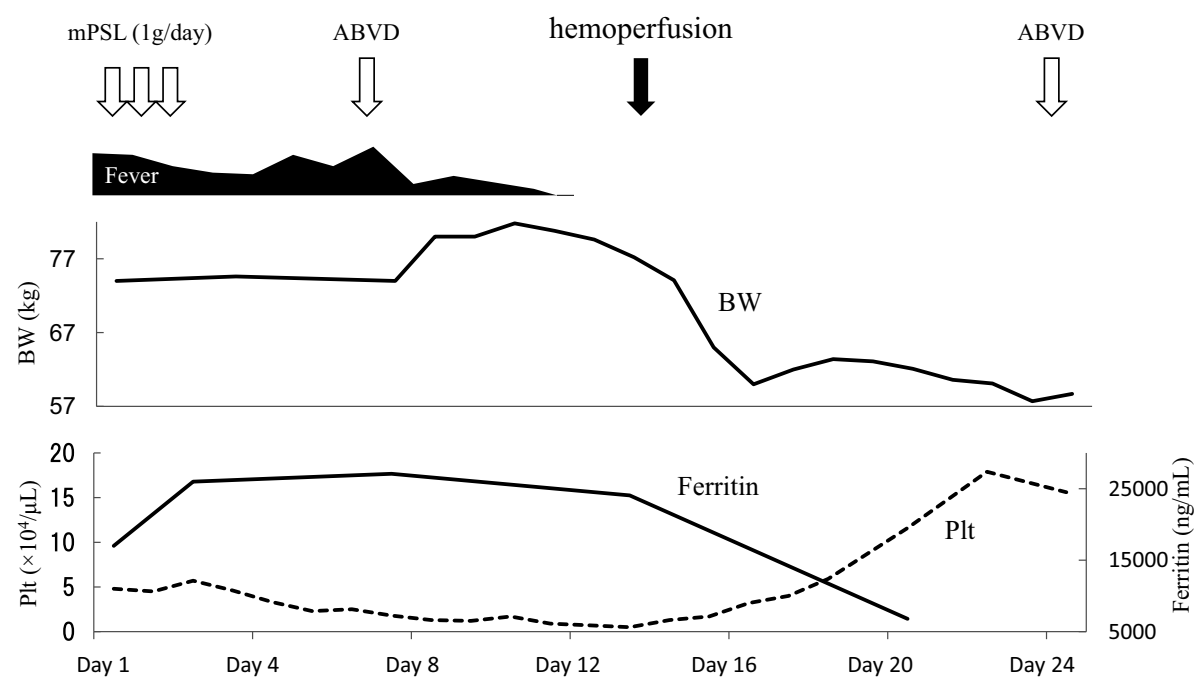

Figure 3. The patient's clinical course. ABVD: doxorubicin, bleomycin, vinblastine and dacarbazine, mPSL: methylprednisolone, BW: body weight

apy had an assertive therapeutic effect on the Hodgkin lymphoma. Nevertheless, the clinical symptoms of HLH persisted.

Cytokine storms result from a positive activation loop in which cytokines, such as interferon- $\gamma$ and tumor necrosis factor- $\alpha$ released from activated $\mathrm{T}$ cells further reinforce activity of these cells to release more cytokines. We speculated that this activation loop was being maintained even after the Hodgkin lymphoma improved with chemotherapy. Since cytokine storms precipitate $\operatorname{HLH}(2,12,13)$, we thought that suppressing HLH required blocking this activation loop. For this purpose, we began hemoperfusion with a polymyxin Bimmobilized fiber column. This column was developed to adsorb and remove endotoxin. However, it has also been used to remove cytokines for improving the pathophysiology of adult respiratory distress syndrome (14) and idiopathic pulmonary fibrosis (15), both of which also accompany hypercytokinemia. In the present case, HLH rapidly improved with hemoperfusion using the column. It remains possible that the column mainly removed endotoxin resulting in suppression of cytokine production from activated $\mathrm{T}$ cells and macrophages. However, endotoxin had not been detected in his blood, and no bacteria were isolated from his blood culture. These results suggest that the column's effects were not due to removal of endotoxin but rather to the direct removal of cytokines. It has also been shown that the column could remove monocytes (16); therefore, it is possible that the removal of activated monocyte-macrophage lineage cells suppressed phagocytosis. However, in our patient all HLHrelated clinical symptoms, including circulatory failure, disappeared following hemoperfusion. Therefore, it is likely that the removal of these cells was incidental to the effect of the column.

Unfortunately, the blood concentrations of the cytokines were not determined before or after treatment. However, it is unlikely that the removal of endotoxin or monocytes was involved in the improvement of HLH in the patient. Therefore, it is highly probable that direct elimination of the cytokines resulted in the blockage of the cytokine-immunocyte activation loop, thus leading to mitigation of the cytokine storm.

In conclusion, the direct removal of cytokines using a 
polymyxin B-immobilized fiber column is therefore considered to be an effective option to save intractable HLH patients, particularly when HLH persists after treatment for an underlying condition. However, further studies are necessary to confirm the usefulness of this strategy.

The authors state that they have no Conflict of Interest (COI).

\section{Acknowledgement}

The authors wish to thank Gary Baley for his editing assistance.

\section{References}

1. Henter JI, Horne A, Aricó M, et al. HLH-2004: Diagnostic and therapeutic guidelines for hemophagocytic lymphohistiocytosis. Pediatr Blood Cancer 48: 124-131, 2007.

2. Rosado FG, Kim AS. Hemophagocytic lymphohistiocytosis: an update on diagnosis and pathogenesis. Am J Clin Pathol 139: 713727, 2013.

3. Ishii E, Ohga S, Imashuku S, et al. Nationwide survey of hemophagocytic lymphohistiocytosis in Japan. Int J Hematol 86: 58-65, 2007.

4. Hagihara M, Inoue M, Hua J, Iwaki Y. Lymphocyte-depleted Hodgkin lymphoma complicating hemophagocytic lymphohistiocytosis as an initial manifestation: a case report and review of the literature. Intern Med 51: 3067-3072, 2012.

5. Hasselblom S, Linde A, Ridell B. Hodgkin's lymphoma, EpsteinBarr virus reactivation and fatal haemophagocytic syndrome. J Intern Med 255: 289-295, 2004.

6. Canellos GP, Anderson JR, Propert KJ, et al. Chemotherapy of advanced Hodgkin's disease with MOPP, ABVD, or MOPP alternating with ABVD. N Engl J Med 327: 1478-1484, 1992.
7. Yokoyama T, Tateishi $\mathrm{K}$, Tsushima $\mathrm{K}$, et al. A case of severe ARDS caused by novel swine-origin influenza (A/H1N1pdm) virus: a successful treatment with direct hemoperfusion with polymyxin B-immobilized fiber. J Clin Apher 25: 350-353, 2010.

8. Cruz DN, Perazella MA, Bellomo R, et al. Effectiveness of polymyxin B-immobilized fiber column in sepsis: a systematic review. Crit Care 11: R47, 2007.

9. Cruz DN, Antonelli M, Fumagalli R, et al. Early use of polymyxin B hemoperfusion in abdominal septic shock: the EUPHAS randomized controlled trial. JAMA 301: 2445-2452, 2009.

10. Ménard F, Besson C, Rincé $P$, et al. Hodgkin lymphomaassociated hemophagocytic syndrome: a disorder strongly correlated with Epstein-Barr virus. Clin Infect Dis 47: 531-534, 2008.

11. Canellos GP, Anderson JR, Propert KJ, et al. Chemotherapy of advanced Hodgkin's disease with MOPP, ABVD, or MOPP alternating with ABVD. N Engl J Med 327: 1478-1484, 1992.

12. Jordan MB, Hildeman D, Kappler J, et al. An animal model of hemophagocytic lymphohistiocytosis (HLH): CD8+ T cells and interferon gamma are essential for the disorder. Blood 104: 735-743, 2004.

13. Henter JI, Elinder G, Söder O, et al. Hypercytokinemia in familial hemophagocytic lymphohistiocytosis. Blood 78: 2918-2922, 1991.

14. Kushi H, Miki T, Okamaoto K, Nakahara J, Saito T, Tanjoh K. Early hemoperfusion with an immobilized polymyxin B fiber column eliminates humoral mediators and improves pulmonary oxygenation. Crit Care 9: R653-R661, 2005.

15. Oishi K, Mimura-Kimura $Y$, Miyasho $T$, et al. Association between cytokine removal by polymyxin B hemoperfusion and improved pulmonary oxygenation in patients with acute exacerbation of idiopathic pulmonary fibrosis. Cytokine 61: 84-89, 2013.

16. Tsujimoto H, Ono S, Hiraki S, et al. Hemoperfusion with polymyxin B-immobilized fibers reduced the number of CD16+ CD14+ monocytes in patients with septic shock. J Endotoxin Res 10: 229-237, 2004.

\section{(C) 2014 The Japanese Society of Internal Medicine http://www.naika.or.jp/imonline/index.html}

